\title{
Local Electronic Structure and Protonic Conductivity in Perovskite-Type Oxide, $\mathrm{SrZrO}_{3}$
}

\author{
Masahito Yoshino, Katsuya Kato, Etty Mutiara, Hiroshi Yukawa and Masahiko Morinaga \\ Department of Materials Science and Engineering, Graduate School of Engineering, Nagoya University, Nagoya 464-8603, Japan
}

Local electronic states around hydrogen and acceptor ions in $\mathrm{SrZrO}_{3}$ are simulated by the DV-X $\alpha$ molecular orbital method to examine their effects on protonic conductivity. The calculated ioncities of the acceptor dopant ion, $\mathrm{M}$, and the surrounding six oxygen ions, $\mathrm{O}_{(i)}(i=1-6)$ are found to change largely with M in the doped oxide, where M's are Yb, Y, In, Al and Ga. There is a clear tendency that the protonic conductivity decreases as these ionocities around the dopant ion, M, deviate further from the ones around the $\mathrm{Zr}$ ion in un-doped oxide. Also, in a geometrical viewpoint, the bond order between $\mathrm{M}_{\text {and }} \mathrm{O}_{(i)}(i=1-6)$ ions is another indication to control the protonic conductivity. The presence of the slightly weaker $\mathrm{M}-\mathrm{O}_{(i)}$ bond than the $\mathrm{Zr}-\mathrm{O}$ bond causes small expansion of the $\mathrm{MO}_{6}$ octahedron, and then gives a nearly symmetrical position for proton to move readily to the neighboring oxygen sites. These results are also found in the other oxides, $\mathrm{BaZrO}_{3}$ and $\mathrm{CaZrO}_{3}$. $\mathrm{Both}$ the ionicity and the bond order are indeed useful parameters for the design of perovskite-type oxides with high protonic conductivity.

(Received December 16, 2004; Accepted April 11, 2005; Published June 15, 2005)

Keywords: Perovskite-type oxide, Protonic conduction, Activation energy, $\mathrm{SrZrO}_{3}, \mathrm{BaZrO}_{3}, \mathrm{CaZrO}_{3}$, Electronic structures

\section{Introduction}

It is known that many perovskite-type oxides (e.g., $\mathrm{SrCeO}_{3}, \mathrm{BaCeO}_{3}, \mathrm{BaZrO}_{3}, \mathrm{CaZrO}_{3}$ ) show protonic conduction at high temperatures when acceptor ions are doped into them. ${ }^{1,2)}$ These oxides have a large potential for use in fuel cells, steam electrolysis and hydrogen gas sensors. ${ }^{3-5)}$

When trivalent cations such as $\mathrm{Y}^{3+}$ are substituted for tetravalent ions such as $\mathrm{Zr}^{4+}$ in $\mathrm{SrZrO}_{3}$, oxygen ion vacancies are introduced into the crystal to keep the charge balance in it. Following the Kröger-Vink notation, this is expressed as,

$$
\mathrm{Y}+\mathrm{Zr}_{\mathrm{Zr}}^{\times}+\frac{1}{2} \mathrm{O}_{\mathrm{O}}^{\times} \rightarrow \mathrm{Y}_{\mathrm{Zr}}^{\prime}+\frac{1}{2} \mathrm{~V}_{\mathrm{O}}^{\bullet \bullet}+\mathrm{Zr}+\frac{1}{4} \mathrm{O}_{2},
$$

where $\mathrm{Y}_{\mathrm{Zr}}^{\prime}$ is a $\mathrm{Y}^{3+}$ ion at the $\mathrm{Zr}^{4+}$ site and $\mathrm{V}_{\mathrm{O}}^{\bullet \bullet}$ is an oxygen ion vacancy. In a wet atmosphere, some of the oxygen ion vacancies are readily filled with an oxygen ion, and interstitial protons, $\mathrm{H}_{\mathrm{i}}^{\bullet}$, are introduced into the crystal. It is expressed as,

$$
\mathrm{H}_{2} \mathrm{O}+\mathrm{V}_{\mathrm{O}}^{\bullet \bullet}=\mathrm{O}_{\mathrm{O}}^{\times}+2 \mathrm{H}_{\mathrm{i}}^{\bullet}
$$

where $\mathrm{O}_{\mathrm{O}}^{\times}$is an oxygen ion at the oxygen site. As a result, protonic conductivity through the interstitial $\mathrm{H}_{\mathrm{i}}^{\bullet}$ is induced in the oxide.

Lots of experiments have been performed in order to elucidate the transport mechanism of proton in the perovskite-type oxides. ${ }^{6-17)}$ For example, as for the crystallographic position of proton, ${ }^{10,11)}$ it has been shown that the proton exists in the neighborhood of the oxygen ion. ${ }^{12)}$ Also, proton appears to exist preferentially in the site near the oxygen ion with a relatively large trapping energy. ${ }^{14,15)}$ In addition, the microscopic mechanism for proton transfer has been studied employing the molecular dynamics simulation. ${ }^{18-22)}$ For example, the time-averaged geometry around the proton at high temperatures is simulated in $\mathrm{BaCeO}_{3}$, $\mathrm{BaZrO}_{3}, \mathrm{SrTiO}_{3}$ and $\mathrm{CaTiO}_{3} .{ }^{21)}$ Also, the activation energy for proton transfer is calculated and corrected with the repulsive interaction of the proton with $\mathrm{B}$ cation $(\mathrm{B}=\mathrm{Ce}, \mathrm{Zr}$, Ti), ${ }^{21)}$ even though the dopant effect is not counted in the calculation.

In most cases, the protonic conduction takes place in the oxide through the hopping of proton from one oxygen ion site to the adjacent site. For the oxides with small lattice constants (e.g., $\mathrm{CaTiO}_{3}$ ) the proton may jump even to the next nearest site. ${ }^{21)}$ The protonic conductivity may be expressed by adopting a general Arrhenius expression for the ionic conductivity, $\sigma$,

$$
\sigma=\frac{A q^{2} c}{k T} \exp \left(-\frac{\Delta H}{k T}\right)
$$

where $A$ is a constant, $q$ is the charge of proton, $c$ is the number of mobile proton, $\Delta H$ is the activation energy for proton transfer including rotation of the $\mathrm{OH}^{-}$hydroxyl ions around the oxygen center, $k$ and $T$ have usual meanings. The magnitude of the conductivity, $\sigma$, is proportional to a preexponential term in the eq. (3), in particular, the number of mobile proton, $c$, and the temperature dependence of $\sigma$ can be seen in the activation energy, $\Delta H$.

Needless to say, such protonic conductivity varies with mother oxides. ${ }^{1,6,23-25)}$ Also, the conductivity varies largely depending on dopant ions. For example, as shown in Fig. 1, protonic conductivity is one or two orders of magnitude different between dopant ions in $\mathrm{SrZrO}_{3}{ }^{24)}$ In this study protonic conduction is mainly concerned at the temperature below $800^{\circ} \mathrm{C}(1073 \mathrm{~K})$ where protonic conduction is dominant. The change with the dopant ions, $\mathrm{M}$, may be attributable mainly to the variation in the activation energy for proton transfer, $\Delta H$. It changes in the order, $\mathrm{Yb} \leq \mathrm{Y}<$ In $<\mathrm{Al} \approx \mathrm{Ga}$. In case of $\mathrm{BaZrO}_{3}$, the order is $\mathrm{Y}<\mathrm{Gd}<$ In $<$ Sc. ${ }^{7)}$

Recently, we have reported the calculated electronic structures of $\mathrm{SrTiO}_{3}$ and $\mathrm{SrZrO}_{3}$ by the DV-X $\alpha$ molecular orbital method and shown that charge compensation takes place among the impurities or defects such as proton, oxygen ion vacancy and acceptor dopant in the oxides. ${ }^{26,27)}$ Also, it is shown that the nature of the chemical bond between constituent ions changes largely by the addition of acceptor dopant and affects protonic conductivity in some ways. The 


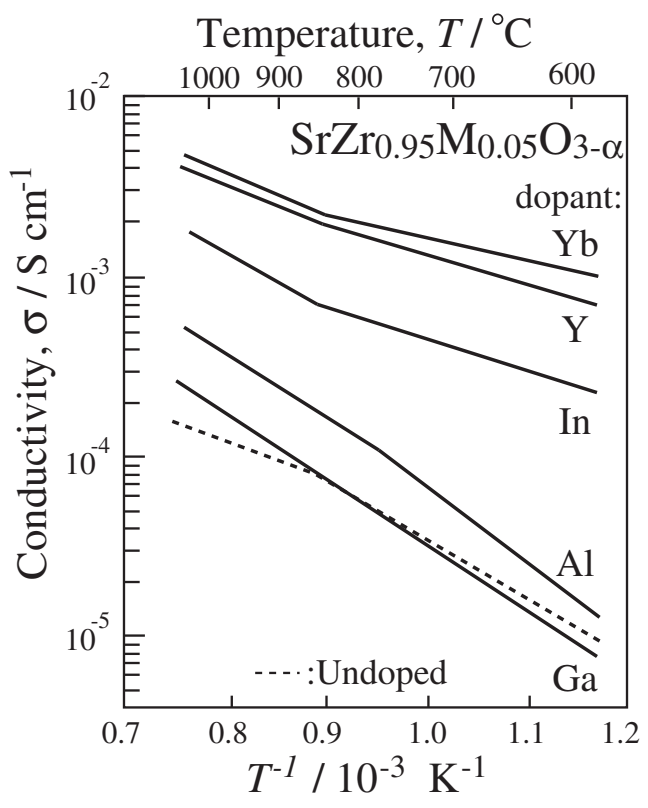

Fig. 1 Protonic conductivity in $\mathrm{SrZrO}_{3} .{ }^{24)}$

idea of chemical matching for proton transfer has been proposed by us ${ }^{27)}$ and also by Kreuer et al. ${ }^{7)}$ In addition, we have simulated local geometries around acceptor dopant ion and proton in $\mathrm{SrZrO}_{3}$ using the plane-wave psudopotential method. ${ }^{28-30)}$ It is found that the introduction of proton and/ or acceptor dopant (e.g., Y, $\mathrm{Al}$ ) into $\mathrm{SrZrO}_{3}$ induces a large local lattice distortion.

In this study, local electronic states in the perovskite-type oxide, $\mathrm{SrZrO}_{3}$, have been calculated by the DV-X $\alpha$ molecular orbital method in order to understand how acceptor dopant ions affect local electronic states and play a role in protonic conduction in the perovskite-type oxides. The activation energy shown in Fig. 1 will be discussed in the light of the calculated local electronic states around the dopant ions and proton.

\section{DV-X $\alpha$ Cluster Method and Cluster Models}

\subsection{DV-X $\alpha$ cluster method}

The DV-X $\alpha$ cluster method ${ }^{31,32)}$ is a molecular orbital calculating method, assuming the Hartree-Fock-Slater (HFS) approximation. In this calculation, the exchange-correlation between electrons is given by the Slater's X $\alpha$ potential. The matrix elements of Hamiltonian and the overlap integrals are calculated by a random sampling method. The molecular orbitals are constructed by a liner combination of numerically generated atomic orbitals (LCAO). The atomic orbitals used in this calculation are $1 \mathrm{~s}-6 \mathrm{p}$ for $\mathrm{Nd}$, Dy and $\mathrm{Yb}, 1 \mathrm{~s}-6 \mathrm{~s}$ for $\mathrm{Ba}$, $1 \mathrm{~s}-5 \mathrm{~d}$ for $\mathrm{In}, 1 \mathrm{~s}-5 \mathrm{p}$ for $\mathrm{Zr}$ and $\mathrm{Y}, 1 \mathrm{~s}-5 \mathrm{~s}$ for $\mathrm{Sr}, 1 \mathrm{~s}-4 \mathrm{~d}$ for $\mathrm{Ga}$, $1 s-4 p$ for $\mathrm{Sc}$ and $\mathrm{Ca}, 1 \mathrm{~s}-3 \mathrm{~d}$ for $\mathrm{Al}, 1 \mathrm{~s}-2 \mathrm{p}$ for $\mathrm{O}$ and $1 \mathrm{~s}$ for hydrogen.

For a characterization of the electronic structures and chemical bonding in the cluster, the energy level structures are obtained from the present calculation. The electron densities of states are also calculated from the energy level structures using the overlapping Gaussian functions with the half width of $0.1 \mathrm{eV}^{31)}$ Population analyses are made in the standard Mulliken's manner. ${ }^{33-36)}$ The overlap population between the $i$-th atomic orbital and the $j$-th atomic orbital at the $l$-th molecular orbital is given by,

$$
Q_{i j}^{l}=C_{i l} C_{j l} S_{i j}
$$

where $S_{i j}$ is the overlap integral given by,

$$
\int \chi_{i}^{*}(r) \chi_{j}(r) d r=S_{i j}
$$

$\chi_{i}$ and $C_{i l}$ are the $i$-th atomic orbital and its coefficient for the $l$-th molecular orbital. The overlap population between atoms $\mathrm{A}$ and $\mathrm{B}$ at the $l$-th molecular orbital is given by,

$$
Q_{\mathrm{AB}}^{l}=\sum_{i \in \mathrm{A}} \sum_{j \in \mathrm{B}} Q_{i j}^{l} \text {. }
$$

The sum over occupied orbitals is the bond-overlap population, $Q_{\mathrm{AB}}$, which is defined by,

$$
Q_{\mathrm{AB}}=\sum_{l} f_{l} Q_{\mathrm{AB}}^{l}
$$

where $f_{l}$ is the occupation number of the $l$-th molecular orbital. Here, this $Q_{\mathrm{AB}}$ is called the bond order. The orbital population of the $i$-th orbital is given by,

$$
Q_{i}=\sum_{l} f_{l} \sum_{j} Q_{i j}^{l}
$$

The net charge of each atom $\Delta Q_{\mathrm{A}}$ is obtained by,

$$
\Delta Q_{\mathrm{A}}=Z_{\mathrm{A}}-\sum_{i \in \mathrm{A}} Q_{i},
$$

where $Z_{\mathrm{A}}$ is the atomic number of atom A. Here, the net charge is called the ionicity. Further detailed explanation of the calculation method is given elsewhere. ${ }^{37-39)}$

\subsection{Cluster models}

The cluster model used is shown in Fig. 2(a). It is constructed on the basis of the crystal structure of $\mathrm{SrZrO}_{3}$ which is orthorhombic, and the space group is Pnma. ${ }^{40)}$ The lattice parameters used are the same values as in bulk, $a=0.58151 \mathrm{~nm}, b=0.81960 \mathrm{~nm}, c=0.57862 \mathrm{~nm}$. According to our previous calculations, ${ }^{41)}$ the calculated electronic structure is not sensitive to the slight lattice parameter change with temperatures in this oxide. So, the calculated ionicities and bond orders are supposed to be less dependent on the tempareture. In order to take into account of the Madelung potential between ions, a space with the size of about

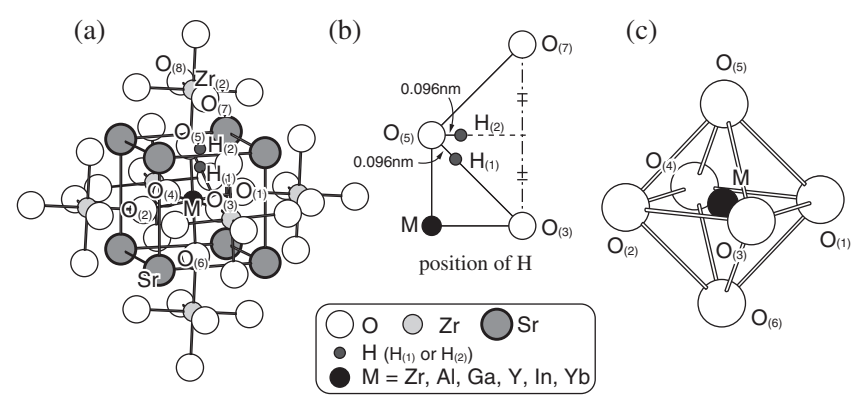

Fig. 2 (a) Cluster model used in the calculations, (b) schematic illustration of the hydrogen positions, and (c) octahedron around a dopant ion, M. 
$8 \times 8 \times 8 \mathrm{~nm}$ is set around the cluster and point charges of formal values are arranged at every position of ions inside this space. The values are $+2,+4$ and -2 for $\mathrm{Sr}, \mathrm{Zr}$, and $\mathrm{O}$ in $\mathrm{SrZrO}_{3}$, respectively.

In order to investigate the effect of the acceptor dopant on the electronic structure, various dopant ions, M, are substituted for the central Zr ion in the cluster, where M's are Al, $\mathrm{Ga}, \mathrm{Y}, \mathrm{In}$, and $\mathrm{Yb}$. As shown in Fig. 2(b), hydrogen, $\mathrm{H}_{(1)}$, is located at the position between the neighboring two oxygen ions, $\mathrm{O}_{(5)}$ and $\mathrm{O}_{(3)}$. Also, $\mathrm{H}_{(2)}$ is located on the bisectors of two oxygen-oxygen connection lines as shown in Fig. 2(b). ${ }^{15)}$ These positions are close to an oxygen ion, $\mathrm{O}_{(5)}$, and the $\mathrm{O}_{(5)}-\mathrm{H}_{(i)}$ distance is set to be $0.096 \mathrm{~nm}$, following the experimental result. ${ }^{15)}$ This $\mathrm{O}-\mathrm{H}$ distance is close to the value in the free $\mathrm{O}-\mathrm{H}$ molecule. While these two positions are possible in the crystal, explanation will be focused mainly on the $\mathrm{H}_{(2)}$ case, because the proton position in $\mathrm{SrZrO}_{3}$ calculated by the psudopotential method is close to the $\mathrm{H}_{(2)}$ site. ${ }^{28-30)}$

Also, as shown in Fig. 2(c), M is surrounded by six oxygen ions, $\mathrm{O}_{(i)}(i=1-6)$. In this study, special attention is directed toward the local electronic states in this small octahedron, because of relatively large bond changes induced there by doping. Here, the geometries are not optimized in the present cluster calculation, both hydrogen and acceptor ion, M, are just located in the undistorted lattice. The effect of geometrical changes with doping will be discussed later with the aid of the results obtained by the psudopotential method.

At the beginning of the calculation, the formal charge is assumed to be +4 for $\mathrm{M}_{\mathrm{Zr}}$ ion, the same value as $\mathrm{Zr}_{\mathrm{Zr}}^{\times}$, but to be neutral for hydrogen in order to keep the charge balance in the cluster, ${ }^{26,27)}$ although the effective charge is determined from the calculation following the Mulliken's population analysis as explained earlier.

In order to show the cluster models, simple notations are used in this paper. For example, pure $\mathrm{SrZrO}_{3}$ cluster means a $\left[\mathrm{ZrZr}_{6} \mathrm{Sr}_{8} \mathrm{O}_{36}\right]^{-28}$ cluster which contains neither $\mathrm{M}$ nor $\mathrm{H}_{(i)}$. Also, $\mathrm{SrZrO}_{3}+\mathrm{H}_{(i)}$ cluster means that only $\mathrm{H}_{(i)}$ is introduced into pure $\mathrm{SrZrO}_{3}$ cluster, $\mathrm{SrZrO}_{3}+\mathrm{M}_{\mathrm{Zr}}$ cluster means that only $\mathrm{M}$ is introduced into pure $\mathrm{SrZrO}_{3}$ cluster, and $\mathrm{SrZrO}_{3}+$ $\mathrm{M}_{\mathrm{Zr}}+\mathrm{H}_{(i)}$ cluster means that both $\mathrm{M}$ and $\mathrm{H}_{(i)}$ are introduced into pure $\mathrm{SrZrO}_{3}$ cluster. Each cluster size is $\left[\mathrm{H}_{(i)} \mathrm{ZrZr}_{6}\right.$ $\left.\mathrm{Sr}_{8} \mathrm{O}_{36}\right]^{-28}$ for $\mathrm{SrZrO}_{3}+\mathrm{H}_{(i)}$ cluster, $\left[\mathrm{MZr}_{6} \mathrm{Sr}_{8} \mathrm{O}_{36}\right]^{-28}$ for $\mathrm{SrZrO}_{3}+\mathrm{M}_{\mathrm{Zr}}$ cluster, and $\left[\mathrm{H}_{(i)} \mathrm{MZr}_{6} \mathrm{Sr}_{8} \mathrm{O}_{36}\right]^{-28}$ for $\mathrm{SrZrO}_{3}+$ $\mathrm{M}_{\mathrm{Zr}}+\mathrm{H}_{(i)}$ cluster.

For comparison, the calculation is repeated for $\mathrm{BaZrO}_{3}$ and $\mathrm{CaZrO}_{3}$, by adopting the cluster models shown in Fig. 2, but varing the crystal parameters. The crystal structure of $\mathrm{BaZrO}_{3}$ is cubic, and the space group is $\mathrm{Pm} \overline{3} \mathrm{~m}$ with the lattice parameter of $a=0.41810 \mathrm{~nm} .{ }^{42}$ ) The dopant ions chosen are Ga, Y, In, Nd and Dy. The doping may lower the symmetry, for example, the $\mathrm{Y}$ doping makes the crystal tetragonal. However, the cubic symmetry is still used here for the purpose of comparison among the dopants. On the other hand, the crystal structure of $\mathrm{CaZrO}_{3}$ is orthorhombic, and the space group is Pnma with the lattice parameters, $a=$ $0.57620 \mathrm{~nm}, b=0.80170 \mathrm{~nm}, c=0.55910 \mathrm{~nm}^{43)}$ The dopant ions chosen are Sc, Ga and In.
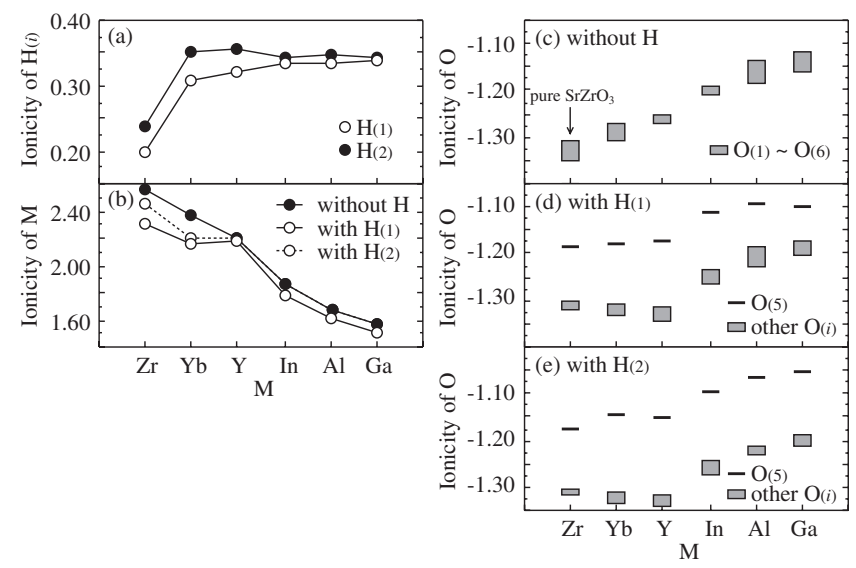

Fig. 3 Ionicity of (a) hydrogen, $\mathrm{H}_{(1)}$ and $\mathrm{H}_{(2)}$, (b) $\mathrm{M}$ ion, and ionicity of $\mathrm{O}$ ions in the $\mathrm{MO}_{6}$ octahedron for the cluster (c) without $\mathrm{H}$, (d) with $\mathrm{H}_{(1)}$, and (e) with $\mathrm{H}_{(2)}$ in $\mathrm{SrZrO}_{3}$.

\section{Results}

\subsection{Energy gap between valence band and conduction band}

From the present calculation of pure $\mathrm{SrZrO}_{3}$, it is found that the valence band and the conduction band consist mainly of $\mathrm{O}-2 \mathrm{p}$ and $\mathrm{Zr}-4 \mathrm{~d}$ components, respectively, and the energy gap lying between these bands is estimated to be about $6 \mathrm{eV}$, in good agreement with experimental results ${ }^{44)}$ and previous calculations. ${ }^{27)}$ It is much larger than the energy gap, $3.5 \mathrm{eV}$, for pure $\mathrm{SrTiO}_{3} \cdot{ }^{26}$

\subsection{Ionicity}

Ionicity of hydrogen and acceptor dopants (i.e., net charges) in $\mathrm{SrZrO}_{3}+\mathrm{H}_{(i)}$ and $\mathrm{SrZrO}_{3}+\mathrm{M}_{\mathrm{Zr}}+\mathrm{H}_{(i)}$ clusters are shown in Fig. 3(a). Here, the result of $\mathrm{M}=\mathrm{Zr}$ denoted in the horizontal axis corresponds to the result for $\mathrm{SrZrO}_{3}+\mathrm{H}_{(i)}$ cluster without any dopant ions. The ionicity of hydrogen is about +0.24 for $\mathrm{SrZrO}_{3}+\mathrm{H}_{(2)}$ cluster, and about +0.34 +0.35 for $\mathrm{SrZrO}_{3}+\mathrm{M}_{\mathrm{Zr}}+\mathrm{H}_{(2)}$ cluster. Thus, when some trivalent dopants coexist with $\mathrm{H}_{(2)}$, the ionicity of hydrogen increases by about $+0.10-+0.11$. These results clearly indicate that hydrogen loses more electrons in the neighborhood of the dopant ion. In case of $\mathrm{H}_{(1)}$, the ionicity of hydrogen is slightly smaller than the $\mathrm{H}_{(2)}$ value as shown in Fig. 3(a), but the trend of the ionicity change with $M$ is similar between $\mathrm{H}_{(1)}$ and $\mathrm{H}_{(2)}$. Also, as shown in Fig. 3(b), there is a large change in the ionicity of the dopant ion, M, regardless of the cluster models with and without hydrogen.

It is found from a series of calculaitons that the ionicities of $\mathrm{Sr}$ and $\mathrm{Zr}$ ions in the cluster scarcely change with the dopant ions. In contrast to this, the ionicities of $\mathrm{O}_{(i)}$ ions $(i=1-6)$ in the octahedron shown in Fig. 2(c) are very sensitive to the dopant ions, M. For example, the variation of the $\mathrm{O}_{(i)}$ ionicities is shown in Fig. 3(c) for the $\mathrm{SrZrO}_{3}+\mathrm{M}_{\mathrm{Zr}}$ clusters without hydrogen. It varies significantly with the dopant ions, M. The electron populations on these $\mathrm{O}_{(i)}$ sites decrease by introducing the acceptor dopant, $\mathrm{M}$, into $\mathrm{SrZrO}_{3}$. These changes are accommodated mainly with the ionicity change of $\mathrm{M}$ located at the center of the octahedron. In fact, as indicated by the solid circles in Fig. 3(b), the positive ionicity 
is smaller for $\mathrm{M}$ than for $\mathrm{Zr}$, irrespective of $\mathrm{M}$. Thus, the ionicities of $\mathrm{O}_{(i)}$ ions become less negative with decreasing positive ionicities of $\mathrm{M}$.

Ionicity of oxygen ions sitting on the corners of $\mathrm{MO}_{6}$ octahedron

As shown in Fig. 3(e), in case of $\mathrm{SrZrO}_{3}+\mathrm{H}_{(2)}$, the ionicities of any $\mathrm{O}_{(i)}$ ions $(i=1-6)$ other than the $\mathrm{O}_{(5)}$ ion adjacent to hydrogen, are $-1.30--1.32$, comparable to the values, $-1.31--1.35$, in pure $\mathrm{SrZrO}_{3}$ without $\mathrm{H}_{(2)}$ as shown in Fig. 3(c). Hydrogen acts as a donor, ${ }^{26,27)}$ but its addition never increases the electron population on the $\mathrm{O}_{(5)}$ site, but decreases while showing a charge state approximately similar to a $\left(\mathrm{O}_{(5)} \mathrm{H}_{(2)}\right)^{1-}$ molecule since the ionicity is -1.17 for $\mathrm{O}_{(5)}$ and +0.24 for $\mathrm{H}_{(2)}$. Instead, the hydrogen addition causes a substantial decrease in the positive ionicity of the central $\mathrm{Zr}$ ion from +2.55 to +2.45 , as shown in Fig. 3(b). This is reasonable since the hydrogen donor level appears just below the conduction band which is composed mainly of $\mathrm{Zr}-4 \mathrm{~d} .{ }^{27}$ )

In case of $\mathrm{SrZrO}_{3}+\mathrm{Y}_{\mathrm{Zr}}+\mathrm{H}_{(2)}$ as shown in Fig. 3(e), the ionicity of the $\mathrm{O}_{(5)}$ ion is about -1.15 , comparable to the value, -1.17 in $\mathrm{SrZrO}_{3}+\mathrm{H}_{(2)}$, and the ionicities of the $\mathrm{O}_{(1)}-$ $\mathrm{O}_{(4)}$ and $\mathrm{O}_{(6)}$ ions are in the range of $-1.31--1.34$, which are similar to the values, $-1.31--1.35$ in pure $\mathrm{SrZrO}_{3}$ shown in Fig. 3(c). Thus, when $\mathrm{Y}_{\mathrm{Zr}}$ and $\mathrm{H}_{(2)}$ coexist in the oxide, the ionicities of oxygen ions in the octahedron recover to a large extent to the ones in pure $\mathrm{SrZrO}_{3}$ except for the $\mathrm{O}_{(5)}$ ion. A similar trend is also seen in $\mathrm{SrZrO}_{3}+\mathrm{Yb}_{\mathrm{Zr}}+\mathrm{H}_{(1)}$.

However, such a recovery is relatively small in the cases of $\mathrm{SrZrO}_{3}+\mathrm{In}_{\mathrm{Zr}}+\mathrm{H}_{(2)}, \mathrm{SrZrO}_{3}+\mathrm{Al}_{\mathrm{Zr}}+\mathrm{H}_{(2)}$ and $\mathrm{SrZrO}_{3}+\mathrm{Ga}_{\mathrm{Zr}}+$ $\mathrm{H}_{(2)}$, since the ionicities of the $\mathrm{O}_{(1)}-\mathrm{O}_{(4)}$ and $\mathrm{O}_{(6)}$ ions are less negative as compared to the values in $\mathrm{SrZrO}_{3}+\mathrm{H}_{(2)}$ as shown in Fig. 3(e). This may be attributable to the less positive ionicities of $\mathrm{In}, \mathrm{Al}$ and $\mathrm{Ga}$ as compared to the ionicities of $\mathrm{Yb}$ and $\mathrm{Y}$ as shown in Fig. 3(b). Such a trend is also seen in case of $\mathrm{SrZrO}_{3}+\mathrm{M}_{\mathrm{Zr}}+\mathrm{H}_{(1)}$ as shown in Fig. 3(d). Thus, it is evident that the electronic states of ions in a small octahedron are dependent largely on the dopant ion existing at the center.

Similar results in the ionicity changes are also seen in Fig. 4 for doped $\mathrm{BaZrO}_{3}$ and in Fig. 5 for doped $\mathrm{CaZrO}_{3}$, both of which will be explained later.

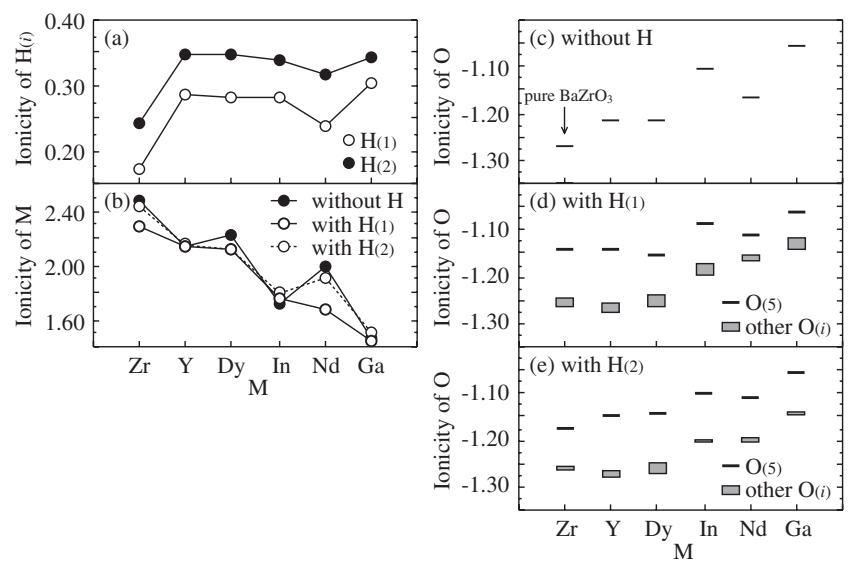

Fig. 4 Ionicity of (a) hydrogen, (b) $\mathrm{M}$ ion, and ionicity of $\mathrm{O}$ ions in the $\mathrm{MO}_{6}$ octahedron for the cluster (c) without $\mathrm{H}$, (d) with $\mathrm{H}_{(1)}$, and (e) with $\mathrm{H}_{(2)}$ in $\mathrm{BaZrO}_{3}$.

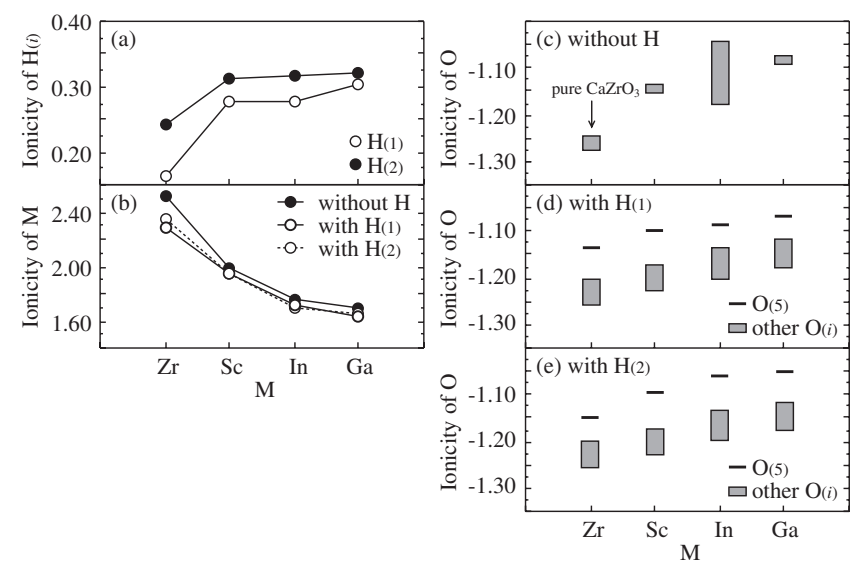

Fig. 5 Ionicity of (a) hydrogen, (b) $\mathrm{M}$ ion, and ionicity of $\mathrm{O}$ ions in the $\mathrm{MO}_{6}$ octahedron for the cluster (c) without $\mathrm{H}$, (d) with $\mathrm{H}_{(1)}$, and (e) with $\mathrm{H}_{(2)}$ in $\mathrm{CaZrO}_{3}$.

\subsection{Bond order}

The covalent bond strength is treatable by using a bond order parameter. The calculated bond orders between ions in the octahedron are found to be modified by the dopant ion, M, and $\mathrm{H}$.

It is apparent from Fig. 6(a) that the value of $\mathrm{O}_{(5)}-\mathrm{H}_{(2)}$ bond order is always larger in $\mathrm{SrZrO}_{3}+\mathrm{M}_{\mathrm{Zr}}+\mathrm{H}_{(2)}$ than in $\mathrm{SrZrO}_{3}+\mathrm{H}_{(2)}$. Therefore, when the hydrogen approaches the $\mathrm{O}_{(5)}$ ion, the $\mathrm{O}_{(5)}-\mathrm{H}_{(2)}$ interaction is strongly enhanced in the vicinity of a $\mathrm{M}_{\mathrm{Zr}}$ ion. In other words, hydrogen tends to be
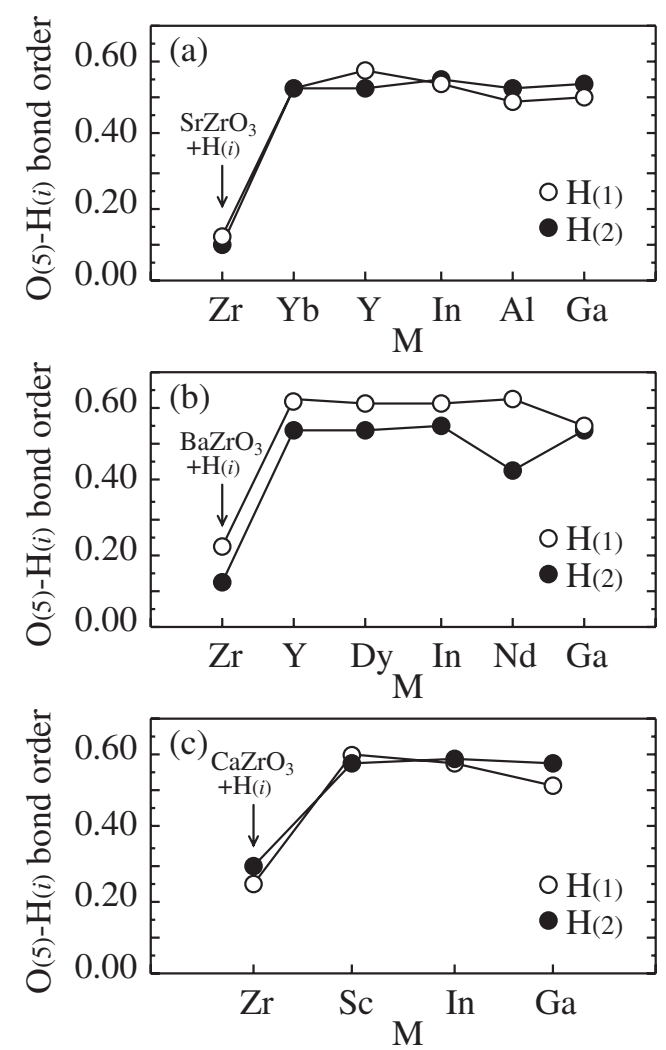

Fig. 6 Changes in the $\mathrm{O}_{(5)}-\mathrm{H}_{(i)}$ bond order with dopant ion, $\mathrm{M}$, in (a) $\mathrm{SrZrO}_{3}$, (b) $\mathrm{BaZrO}_{3}$ and (c) $\mathrm{CaZrO}_{3}$. 
Table 1 List of the bond orders between ions in the cluster of $\mathrm{SrZrO}_{3}$.

\begin{tabular}{lcccrrr}
\hline & $\mathrm{SrZrO}_{3}+\mathrm{H}_{(2)}$ & $\mathrm{SrZrO}_{3}+\mathrm{Yb}_{\mathrm{Zr}}+\mathrm{H}_{(2)}$ & $\mathrm{SrZrO}_{3}+\mathrm{Y}_{\mathrm{Zr}}+\mathrm{H}_{(2)}$ & $\mathrm{SrZrO}_{3}+\mathrm{In}_{\mathrm{Zr}}+\mathrm{H}_{(2)}$ & $\mathrm{SrZrO}_{3}+\mathrm{Al}_{\mathrm{Zr}}+\mathrm{H}_{(2)}$ & $\mathrm{SrZrO}_{3}+\mathrm{GaZr}_{\mathrm{Zr}}+\mathrm{H}_{(2)}$ \\
\hline $\mathrm{O}_{(5)}-\mathrm{M}$ & 0.00 & -0.20 & -0.19 & 0.00 & 0.14 \\
$\mathrm{O}_{(5)}-\mathrm{Zr}_{(2)}$ & -0.03 & -0.04 & -0.04 & -0.03 & -0.02 \\
$\mathrm{O}_{(5)}-\mathrm{H}_{(2)}$ & 0.10 & 0.53 & 0.53 & 0.55 & 0.01 \\
$\mathrm{H}_{(2)}-\mathrm{O}_{(3)}$ & 0.00 & 0.01 & 0.01 & 0.01 & 0.01 & 0.01 \\
$\mathrm{H}_{(2)}-\mathrm{O}_{(7)}$ & 0.00 & 0.01 & 0.01 & -0.01 & 0.01 \\
$\mathrm{M}_{-} \mathrm{H}_{(2)}$ & -0.04 & -0.02 & -0.02 & -0.01 & -0.01 \\
\hline
\end{tabular}

located more preferably near the oxygen ion neighboring the $\mathrm{M}_{\mathrm{Zr}}$ ion than the $\mathrm{Zr}$ ion. Thus, the $\mathrm{M}_{\mathrm{Zr}}$ ion provides a more stable hydrogen site than the $\mathrm{Zr}$ ion. This is also the case of $\mathrm{H}_{(1)}$ as shown in Fig. 6(a). The present calculated result is consistent with the experimented result that proton is located preferably near the oxygen ion neighboring the dopant ion in $\mathrm{SrZrO}_{3} .{ }^{14)}$ Thus, the doping of acceptor ions not only makes the oxygen vacancies, but also gives a chemical situation suitable for forming an $\mathrm{O}-\mathrm{H}$ molecule in the oxide. A similar trend is also seen in Fig. 6(b) for $\mathrm{BaZrO}_{3}$ and in Fig. 6(c) for $\mathrm{CaZrO}_{3}$.

Furthermore, both $\mathrm{H}_{(2)}$ and $\mathrm{O}_{(5)}$ ions interact very weakly with the surrounding ions as shown in Table 1 . The notation of ions used in the table is the same as the one used in Fig. 2(a). For example, $\mathrm{Zr}_{(2)}$ exists just above $\mathrm{O}_{(5)}$ ion. The small or negative bond order means weak or anti-bonding interaction operating between ions. This is seen in the bond order values of $\mathrm{O}_{(5)}-\mathrm{M}, \mathrm{O}_{(5)}-\mathrm{Zr}_{(2)}$ and $\mathrm{M}-\mathrm{H}_{(2)}$, all given in Table 1. So, the present result implies that the $\mathrm{O}_{(5)}-\mathrm{H}_{(2)}$ molecule acts freely as if it is nearly independent of the other ions in the crystal. This may allow proton to rotate rather easily around the $\mathrm{O}_{(5)}$ ion, as suggested in a previous study. ${ }^{18)}$

Also, the variational range of the $\mathrm{M}-\mathrm{O}_{(i)}$ bond orders are shown in Figs. 7(a), (b) and (c) for the clusters without hydrogen, with $\mathrm{H}_{(1)}$ and with $\mathrm{H}_{(2)}$, respectively. They vary significantly with the dopant ions, M. Since $\mathrm{H}_{(1)}$ or $\mathrm{H}_{(2)}$, is bound to the $\mathrm{O}_{(5)}$ ion, the $\mathrm{M}-\mathrm{O}_{(5)}$ bond order is different largely from the other $\mathrm{M}-\mathrm{O}_{(i)}(i=1-4,6)$ bond orders in the hydrogen-containing cluster. It is also seen from Fig. 7(a) that both the $\mathrm{Yb}-\mathrm{O}$ and the $\mathrm{Y}-\mathrm{O}$ bond orders are smaller than the $\mathrm{Zr}-\mathrm{O}$ bond order, but the $\mathrm{In}-\mathrm{O}, \mathrm{Al}-\mathrm{O}$ and $\mathrm{Ga}-\mathrm{O}$ bond orders are larger than the $\mathrm{Zr}-\mathrm{O}$ bond order in the hydrogenfree cluster. A similar trend is seen in the hydrogencontaining cluster. In other words, the change in the $\mathrm{M}-\mathrm{O}$ covalent bond strength with doping is similar, irrespective of the hydrogen-free or containing cluster. Also, the $\mathrm{M}-\mathrm{O}$ bond order deviates from the $\mathrm{Zr}-\mathrm{O}$ bond order in the order, $\mathrm{Yb}-\mathrm{O} \leq \mathrm{Y}-\mathrm{O}<\mathrm{In}-\mathrm{O}<\mathrm{Al}-\mathrm{O} \approx \mathrm{Ga}-\mathrm{O}$. This trend of the local covalent bond observed in $\mathrm{SrZrO}_{3}$ also appears in acceptor-doped $\mathrm{BaZrO}_{3}$ and $\mathrm{CaZrO}_{3}$ as shown in Fig. 8 and Fig. 9, respectively. Namely, the $\mathrm{M}-\mathrm{O}$ bond order deviates from the $\mathrm{Zr}-\mathrm{O}$ bond order approximately in the order, $\mathrm{Y}-\mathrm{O}<\mathrm{Dy}-\mathrm{O}<\mathrm{In}-\mathrm{O}<\mathrm{Nd}-\mathrm{O}<\mathrm{Ga}-\mathrm{O}$, in $\mathrm{BaZrO}_{3}$, even though it shows either negative or positive deviation. In case of $\mathrm{CaZrO}_{3}$, the order is $\mathrm{Sc}-\mathrm{O}<\mathrm{In}-\mathrm{O}<\mathrm{Ga}-\mathrm{O}$.

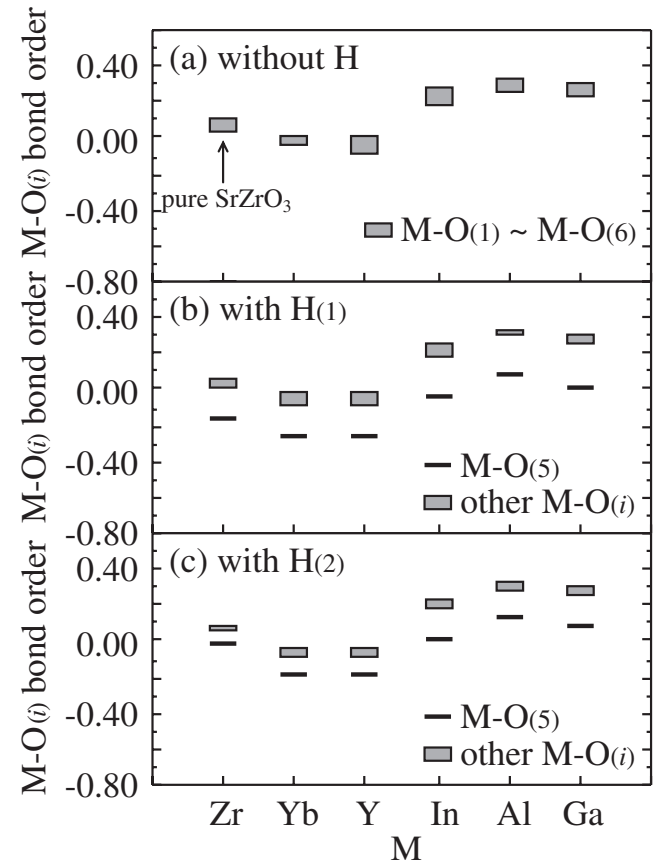

Fig. $7 \mathrm{M}-\mathrm{O}_{(i)}$ bond order in the $\mathrm{MO}_{6}$ octahedron for the cluster (a) without $\mathrm{H}$, (b) with $\mathrm{H}_{(1)}$, and (c) with $\mathrm{H}_{(2)}$ in $\mathrm{SrZrO}_{3}$.

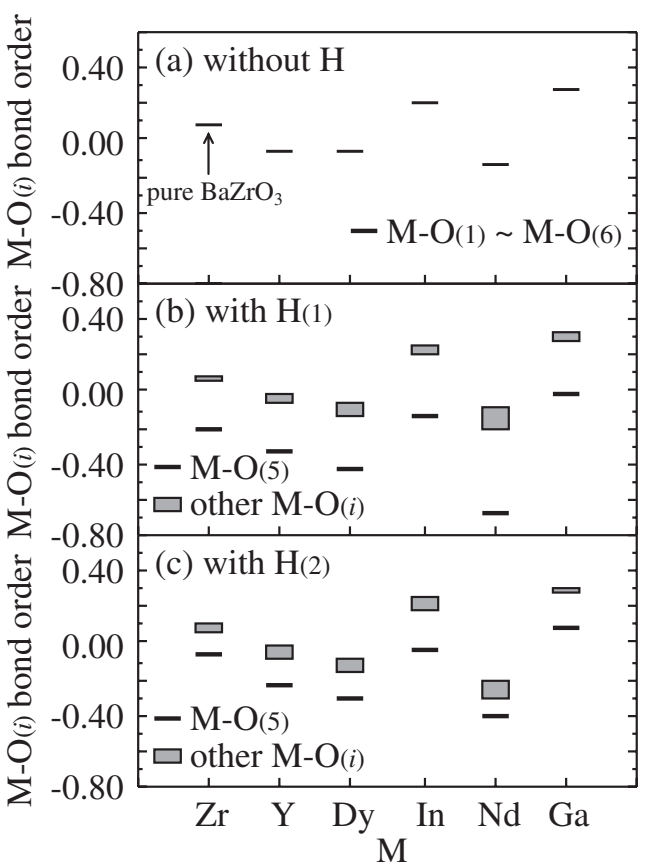

Fig. $8 \mathrm{M}-\mathrm{O}_{(i)}$ bond order in the $\mathrm{MO}_{6}$ octahedron for the cluster (a) without $\mathrm{H}$, (b) with $\mathrm{H}_{(1)}$, and (c) with $\mathrm{H}_{(2)}$ in $\mathrm{BaZrO}_{3}$. 


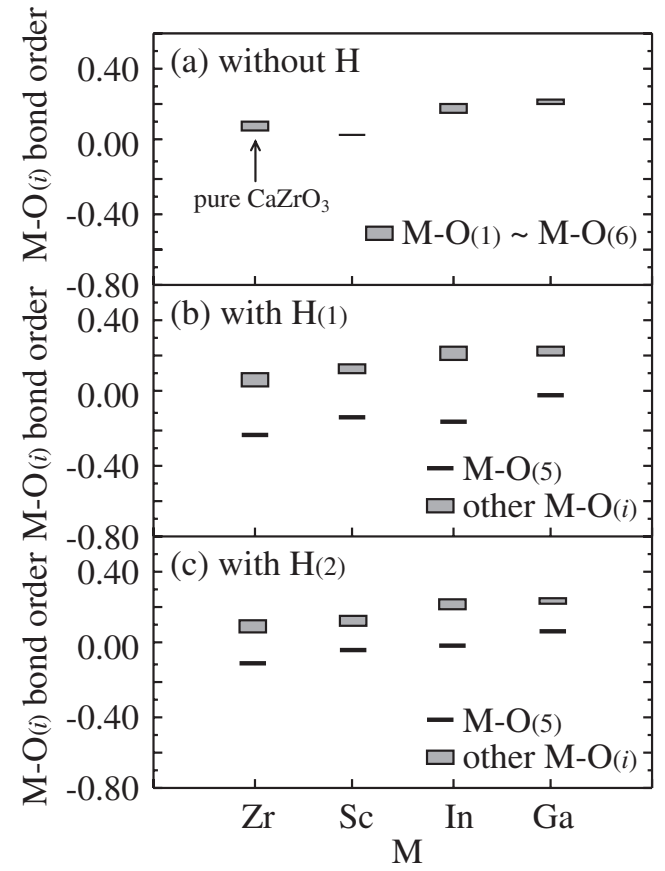

Fig. $9 \mathrm{M}-\mathrm{O}_{(i)}$ bond order in the $\mathrm{MO}_{6}$ octahedron for the cluster (a) without $\mathrm{H}$, (b) with $\mathrm{H}_{(1)}$, and (c) with $\mathrm{H}_{(2)}$ in $\mathrm{CaZrO}_{3}$.

\section{Discussion}

The present simulation is not dynamic but static, so it may be difficult for the dynamical behavior of protonic conduction to be treated following the present result alone. However, it still provides us with information of the protonic conduction through the local electronic structure around hydrogen and acceptor dopant ions. The present calculation does not involve any changes in local geometries attendant on the introduction of hydrogen and acceptor ion into the oxide lattice. In our recent study, such local geometries around hydrogen and acceptor ion have been investigated by the first-principles density functional calculations. ${ }^{28-30)}$ By comparing the present study with the previous study, we can discuss the mechanism of protonic conduction in a qualitative way. As a result, some guiding principles for materials design will be obtained through the comparison.

As explained earlier, the doping of acceptor elements modifies the ionicities of oxygen ions and the bond orders between metal and oxygen ions in a small octahedron where an acceptor dopant is located in the center. In other words, the doping effect reflects mainly the nature of the chemical bond between ions in such an octahedron. So, the local electronic structure in the octahedron is considered to be important in understanding the protonic conduction in this oxide, even though a number of proton trapped by dopant ions will decrease with increasing temperature. ${ }^{45)}$

\subsection{Correlation between protonic conductivity and local charge state}

As shown in Fig. 3, the ionicities of $\mathrm{H}_{(i)}$ and $\mathrm{O}_{(i)}$ ions in the octahedron where an acceptor dopant is located in the center, are modified largely by doping. Also, as shown in Fig. 6, the doping affects the O-H bond order significantly. In $\mathrm{SrZrO}_{3}$, the covalent bond between $\mathrm{H}_{(i)}$ and $\mathrm{O}_{(5)}$ ions is relatively strong, and it becomes stronger in the presence of dopant ions in the neighborhood as mentioned before. This means that $\mathrm{H}$ is bound to the oxygen ion near the dopant $\mathrm{M}$ ion or $\mathrm{Zr}$ ion, so that the thermal activation is more or less needed to relax the $\mathrm{O}-\mathrm{H}$ bond for proton transfer.

The activation energy for proton transfer seems to be lowered if the local ionic states of ions are similar between those octahedra which are concerned with proton transfer. If the difference in their ionic states is larger, more adjustment in the local electronic state is needed to make a transition state for proton transfer, resulting in the higher activation energy, although this discussion is qualitative without any calculations of the transition state. So, the activation energy of the M-doped $\mathrm{SrZrO}_{3}$ is supposed to be smaller when there is a smaller deviation in the ionicity values of $\mathrm{M}$ and $\mathrm{O}$ ions compared to those of $\mathrm{Zr}$ and $\mathrm{O}$ ions in the undoped $\mathrm{SrZrO}_{3}$. Furthermore, it is supposed that the charge of the dopant ion, $\mathrm{M}$, reflects in some ways on the number of mobile protons without trapping near the $\mathrm{M}$ ion. As the Coulomb repulsive interaction operating between proton and $\mathrm{M}$ ion is expected to be weaker in the less positive $\mathrm{M}$ ion, the more trapping will occur in the less positive $\mathrm{M}$ ion. As shown in Fig. 3(b), for example, $\mathrm{Al}$ has less positive ionicity compared to $\mathrm{Y}$. Although the total number of protons introduced into the doped oxide itself still remains unclear in previous experiments, the local charge state around $\mathrm{M}$ and proton may be related closely to the protonic conductivity.

To verify this presumption, the ionicities of constituent elements in the octahedron are illustrated in Fig. 10 for the following nine clusters, $\left(\mathrm{a}_{1}\right)$ pure $\mathrm{SrZrO}_{3},\left(\mathrm{a}_{2}\right) \mathrm{SrZrO}_{3}+\mathrm{H}_{(1)}$, (a $) \mathrm{SrZrO}_{3}+\mathrm{H}_{(2)},\left(\mathrm{b}_{1}\right) \mathrm{SrZrO}_{3}+\mathrm{Y}_{\mathrm{Zr}},\left(\mathrm{b}_{2}\right) \mathrm{SrZrO}_{3}+\mathrm{Y}_{\mathrm{Zr}}+\mathrm{H}_{(1)}$, $\left(b_{3}\right) \mathrm{SrZrO}_{3}+\mathrm{Y}_{\mathrm{Zr}}+\mathrm{H}_{(2)},\left(c_{1}\right) \mathrm{SrZrO}_{3}+\mathrm{Al}_{\mathrm{Zr}},\left(\mathrm{c}_{2}\right) \mathrm{SrZrO}_{3}+$ $\mathrm{Al}_{\mathrm{Zr}}+\mathrm{H}_{(1)}$ and $\left(\mathrm{c}_{3}\right) \mathrm{SrZrO}_{3}+\mathrm{Al}_{\mathrm{Zr}}+\mathrm{H}_{(2)}$. Here, shown in $\left(\mathrm{a}_{2}\right)_{-}$ $\left(c_{2}\right)$ and $\left(a_{3}\right)-\left(c_{3}\right)$, and in $\left(a_{1}\right)-\left(c_{1}\right)$ are octahedra with and
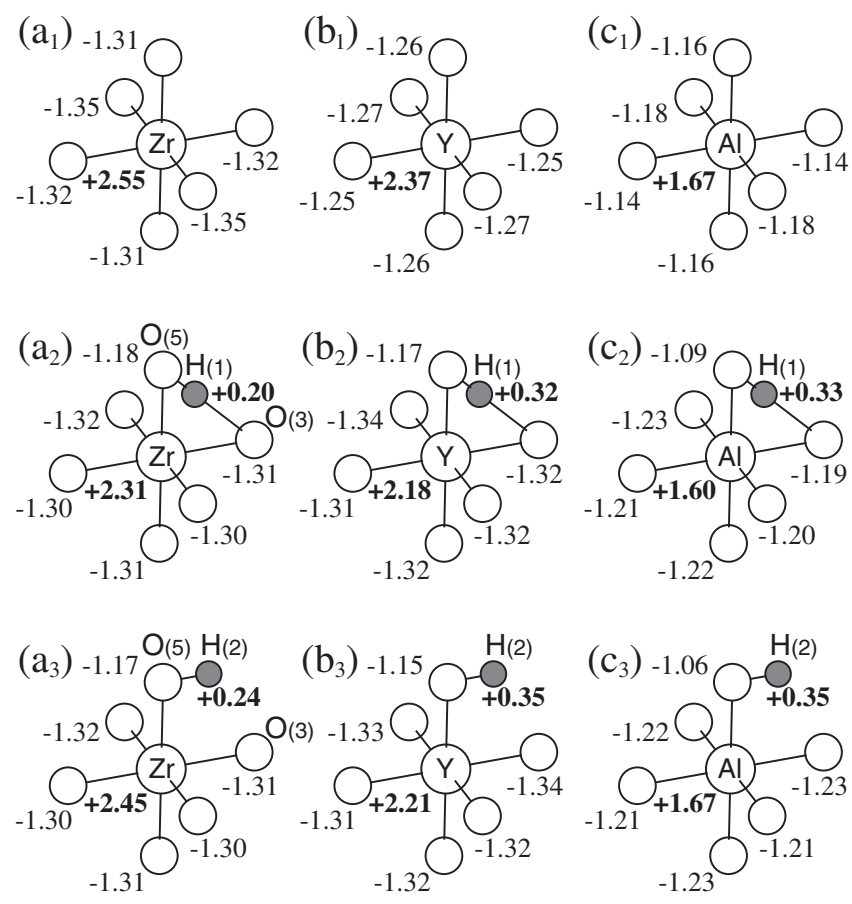

Fig. 10 Local charge states in various $\mathrm{MO}_{6}$ octahedra in $\mathrm{SrZrO}_{3}$. 
without hydrogen in the cluster, respectively. Also, shown in $\left(\mathrm{a}_{2}\right)-\left(\mathrm{c}_{2}\right)$ and $\left(\mathrm{a}_{3}\right)-\left(\mathrm{c}_{3}\right)$ are octahedra containing $\mathrm{H}_{(1)}$ and $\mathrm{H}_{(2)}$, respectively. In the Y-doped $\mathrm{SrZrO}_{3}$, there are at least four octahedra shown in $\left(a_{1}\right),\left(a_{3}\right),\left(b_{1}\right)$ and $\left(b_{3}\right)$, if oxygen ion vacancy around the doped ion is not counted. Here, $\left(a_{1}\right)$ and $\left(a_{3}\right)$ octahedra are seen in the undoped region, and $\left(b_{1}\right)$ and $\left(b_{3}\right)$ octahedra are seen in the Y-doped region. The proton transfer will take place between these octahedra. To show the local charge states in each octahedron, the value of ionicities are presented in the figure.

As shown in this figure, since $\mathrm{H}_{(2)}$ is bound to the $\mathrm{O}_{(5)}$ ion, the ionicity of $\mathrm{O}_{(5)}$ differs largely from that of $\mathrm{O}_{(i)}(i=1-4$, $6)$. So, the ionicities of $\mathrm{O}_{(1)}-\mathrm{O}_{(4)}$ and $\mathrm{O}_{(6)}$ are assumed to represent the ionic state of oxygen ions around hydrogen in the following discussion. It is noticed that the ionicities of these $\mathrm{O}$ ions are $-1.30--1.32$ in $\mathrm{SrZrO}_{3}+\mathrm{H}_{(2)}$ shown in $\left(\mathrm{a}_{3}\right)$ and they are very similar to the values, $-1.31--1.34$, in $\mathrm{SrZrO}_{3}+\mathrm{Y}_{\mathrm{Zr}}+\mathrm{H}_{(2)}$ shown in $\left(\mathrm{b}_{3}\right)$, but very different from the values, $-1.21--1.23$, in $\mathrm{SrZrO}_{3}+\mathrm{Al}_{\mathrm{Zr}}+\mathrm{H}_{(2)}$ shown in $\left(\mathrm{c}_{3}\right)$. In addition, the ionicities of $\mathrm{M}$ ion are +2.45 for $\mathrm{Zr}$ ion in $\left(\mathrm{a}_{3}\right),+2.21$ for $\mathrm{Y}$ ion in $\left(\mathrm{b}_{3}\right)$ and +1.67 for $\mathrm{Al}$ ion in $\left(\mathrm{c}_{3}\right)$. Thus, judging from the local ionic states of the octahedra shown in $\left(a_{3}\right),\left(b_{3}\right)$ and $\left(c_{3}\right)$, the $Y$-doped oxide resembles pure $\mathrm{SrZrO}_{3}$ but such resemblance is not seen in the Al-doped oxide. This is also the case for the hydrogen-free octahedra shown in $\left(a_{1}\right),\left(b_{1}\right)$ and $\left(c_{1}\right)$. These characteristics also can be seen in Fig. 3. Therefore, it may be said that proton can transfer more easily between the four octahedra, $\left(a_{1}\right),\left(b_{1}\right)$, $\left(a_{3}\right)$ and $\left(b_{3}\right)$, in the Y-doped oxide than between the four octahedra, $\left(a_{1}\right),\left(c_{1}\right),\left(a_{3}\right)$ and $\left(c_{3}\right)$, in the Al-doped oxide. This is because, the less adjustment in the local electronic states is needed to make a transition state for proton transfer in the former oxide than in the latter oxide. Also, the trapping effect is less significant in the Y-doped oxide than in the Aldoped oxide. Thus, a local charge state is a measure of the conductivity change with doping.

This discussion is also valid in the case of $\mathrm{H}_{(1)}$, since the difference in the local ionic states is rather small between $\mathrm{H}_{(1)}$ and $\mathrm{H}_{(2)}$ as shown in Fig. 10 and Fig. 3. Thus, protonic conductivity is supposed to be larger in the Y-doped oxide than the Al-doped oxide. Furthermore, according to the comparison in the ionicities among the octahedra in the other doped oxides shown in Fig. 3, it is predicted that the proton mobility changes in the order, $\mathrm{Yb} \geq \mathrm{Y}>\mathrm{In}>\mathrm{Al} \approx \mathrm{Ga}$. This is consistent with the order of the measured proton conductivity shown in Fig. 1. ${ }^{24)}$

This trend of the local charge changes observed in $\mathrm{SrZrO}_{3}$ also appears in the acceptor-doped $\mathrm{BaZrO}_{3}$ and $\mathrm{CaZrO}_{3}$. For $\mathrm{BaZrO}_{3}$, it is supposed from Fig. 4 that the protonic conductivity changes in the order, $\mathrm{Y} \approx \mathrm{Dy}>\mathrm{In} \approx \mathrm{Nd}>$ $\mathrm{Ga}$. This is consistent with the order of the measured protonic conductivity. ${ }^{23)}$ Kreuer et al. ${ }^{7)}$ has reported that $\mathrm{Y}$ is the best dopant which chemically matches to the $\mathrm{Zr}$ in $\mathrm{BaZrO}_{3}$. Also, for $\mathrm{CaZrO}_{3}$, the protonic conductivity changes in the order, $\mathrm{Sc}>\mathrm{In}>\mathrm{Ga}$, judging from Fig. 5, which is consistent with the order of the measured protonic conductivity. ${ }^{25)}$

There has been a long dispute whether the protonic conductivity is associated in some ways with the ionic radius of dopant ions. ${ }^{46)}$ In case of $\mathrm{SrZrO}_{3}$, Shannon's ionic radii of dopant ions change in the order, $\mathrm{Y} \geq \mathrm{Yb}>\mathrm{In}>\mathrm{Ga}>\mathrm{Al}$, which is, however, different from the order of the protonic conductivities in $\mathrm{SrZrO}_{3}$. This also holds for the accepterdoped $\mathrm{BaZrO}_{3}$ and $\mathrm{CaZrO}_{3}$, judging from the order of the ionic radii, $\mathrm{Nd}>\mathrm{Dy} \approx \mathrm{Y}>\mathrm{In}>\mathrm{Ga}$ for $\mathrm{BaZrO}_{3}$ and $\mathrm{In}>$ $\mathrm{Sc}>\mathrm{Ga}$ for $\mathrm{CaZrO}_{3}$. Thus, it is supposed that the ionicity of the dopant ion affects the protonic conductivity more than the ionic radius.

Furthermore, it is noted here that the calculated ionicity of the dopant, M, is not necessarily related to the electronegativity, since, for example, in the case of $\mathrm{SrZrO}_{3}$, the electronegativity changes in the order, $\mathrm{Y}<\mathrm{Yb}<\mathrm{Zr}<$ $\mathrm{Al}<\mathrm{In}<\mathrm{Ga}$, which is inconsistent with the order of the ionicity of $\mathrm{M}$ shown in Fig. 3(b).

\subsection{Local geometry and activation energy for proton transfer}

Recently, the optimized geometries around hydrogen have been simulated by using the plane-wave psudopotential method. ${ }^{28-30)}$ For convenience of the present discussion, the results in the undoped, Y-doped and $\mathrm{Al}$-doped $\mathrm{SrZrO}_{3}$ are reproduced in Figs. 11(a), (b) and (c), respectively. The hydrogen seems to locate near the $\mathrm{H}_{(2)}$ position, in agreement with the experiment. ${ }^{15)}$ Also, the corresponding bond orders between $\mathrm{M}$ and $\mathrm{O}_{(i)}$ ions in the octahedron are illustrated in Figs. 12(a), (b) and (c), where these bond orders are obtained from the calculation in the undistorted lattice.

It is apparent from Fig. 12 that the $\mathrm{Y}-\mathrm{O}$ bond order is smaller than the $\mathrm{Zr}-\mathrm{O}$ bond order, but the $\mathrm{Al}-\mathrm{O}$ bond order is larger. The weaker $\mathrm{Y}-\mathrm{O}$ bond compared to the $\mathrm{Zr}-\mathrm{O}$ bond implies that the $\mathrm{YO}_{6}$ octahedron expands, whereas the stronger $\mathrm{Al}-\mathrm{O}$ bond implies that the $\mathrm{AlO}_{6}$ octahedron shrinks. In fact, according to the results of optimized geometries shown in Fig. 11, the $\mathrm{YO}_{6}$ octahedron becomes larger than the $\mathrm{Zr}_{(2)} \mathrm{O}_{6}$ octahedron but the $\mathrm{AlO}_{6}$ octahedron becomes smaller, in agreement with the above expectation. Thus, the bond order is a good measure of the local geometrical change with doping, although the difference in the ionic radius between $\mathrm{M}$ (i.e., $\mathrm{Y}>\mathrm{Al}$ ) also reflects the size of the $\mathrm{MO}_{6}$ octahedron.

Also, the $\mathrm{O}-\mathrm{H}$ bond direction rotates toward the acceptor doped octahedron, $\mathrm{MO}_{6}$, since the bond orientation angle, $\alpha$, is $40.3^{\circ}$ in the undoped oxide, but $34.1^{\circ}$ in the Y-doped oxide, $30.7^{\circ}$ in the Al-doped oxide. This result indicates that proton always approaches the acceptor dopant ion through the rotation of $\mathrm{O}-\mathrm{H}$ bond. In general, this may be due to the weaker Coulomb repulsive interaction operating between proton and $\mathrm{M}^{3+}$ acceptor ion than between proton and $\mathrm{Zr}^{4+}$ ion. Thus, the net charge on the $\mathrm{M}$ site influences the position of the proton and probably affects the mobility of proton. ${ }^{6}$ However, the $\mathrm{O}-\mathrm{H}$ bond length is not modified largely by doping, as shown in Fig. 11.

As a result of the size change in the $\mathrm{MO}_{6}$ octahedron and the orientation change in the $\mathrm{O}-\mathrm{H}$ bond, local configurations around $\mathrm{H}$ are modified as shown in Figs. 11(b) and (c). It is noticed that the interionic distances, $\mathrm{H}-\mathrm{O}_{(3)}$ and $\mathrm{H}-\mathrm{O}_{(7)}$, or $\mathrm{H}-\mathrm{Y}$ and $\mathrm{H}-\mathrm{Zr}_{(2)}$, and the orientation angles, $\alpha$ and $\beta$, are similar in the Y-doped oxide as shown in Fig. 11(b). On the other hand, those are quite different in the Al-doped oxide as shown in Fig. 11(c). In other words, the Y doping provides a nearly symmetrical situation for proton to migrate between 
$\mathrm{ZrO}_{6}$ octahedron

MO6 octahedron

(a)

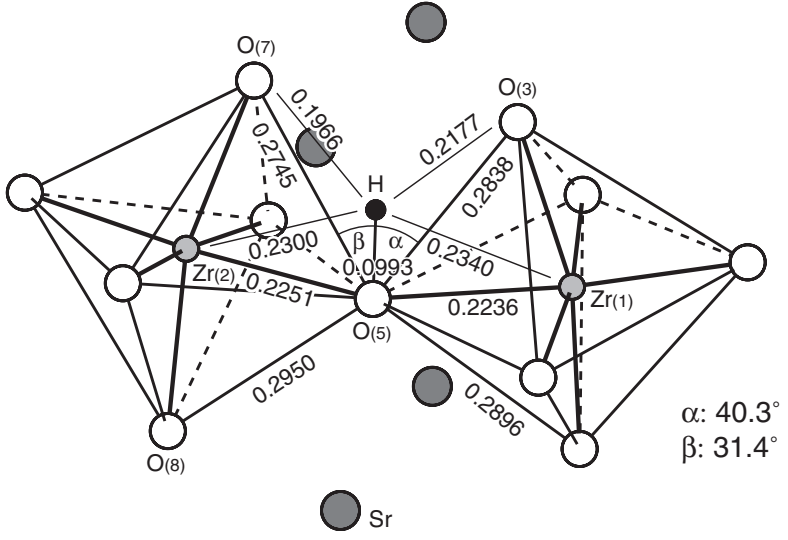

(b)

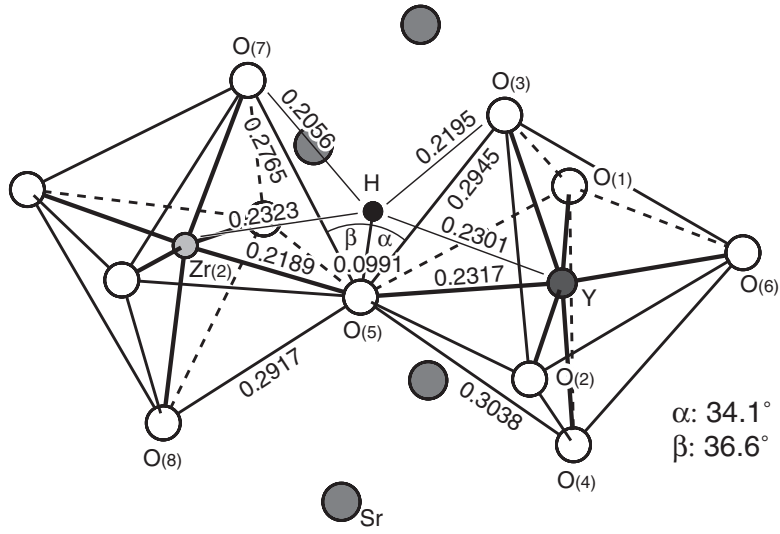

(c)

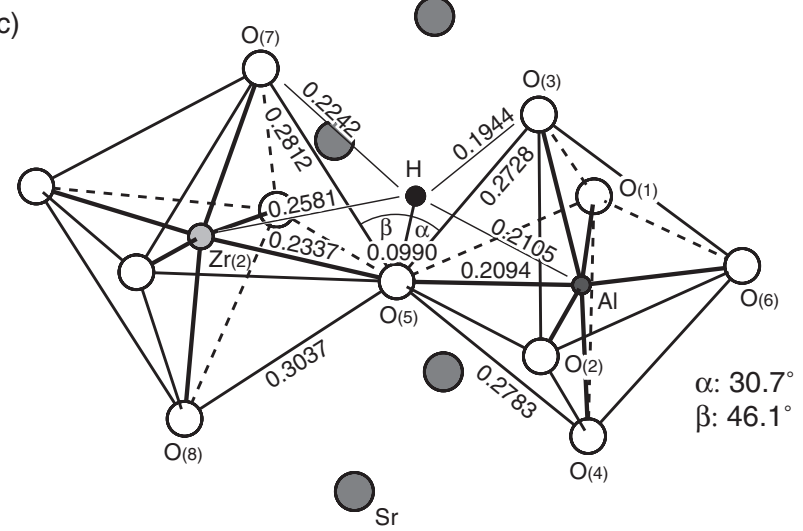

Fig. 11 Optimized local ionic arrangements around (a) $\mathrm{Zr}$ and $\mathrm{H}$, (b) Yand $\mathrm{H}$, and (c) $\mathrm{Al}$ and $\mathrm{H}$ in orthorhombic $\mathrm{SrZrO}_{3}$. In each figure interionic distances are given in the $\mathrm{nm}$ unit.

Bond order
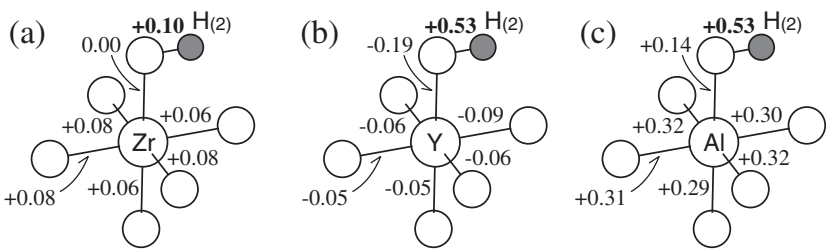

Fig. 12 Bond order between ions in (a) $\mathrm{ZrO}_{6}$, (b) $\mathrm{YO}_{6}$ and (c) $\mathrm{AlO}_{6}$ octahedra, all containing $\mathrm{H}_{(2)}$. two octahedra, $\mathrm{Zr}_{(2)} \mathrm{O}_{6}$ and $\mathrm{YO}_{6}$, whereas the $\mathrm{Al}$ ion doping induces asymmetry. As the $\mathrm{O}-\mathrm{H}$ bond is always inclined toward the $\mathrm{MO}_{6}$ octahedron, the slight expansion of the $\mathrm{YO}_{6}$ octahedron is needed to make a nearly symmetrical configuration, but the shrinkage of the $\mathrm{AlO}_{6}$ octahedron introduces the further asymmetry. In case of the undoped oxide shown in Fig. 11(a), the situation is just intermediate between the Yand Al-doped oxides. Thus, the Y doping seems to give the better situation for proton transfer as compared to the undoped state.

The activation energy for proton transfer has been estimated by taking a difference in the total energies between the saddle point and the most stabilized proton site illustrated in Fig. 11. ${ }^{30)}$ In the proton diffusion process, proton may move from the $\mathrm{O}_{(5)}$ neighbor to either the $\mathrm{O}_{(3)}$ neighbor or the $\mathrm{O}_{(7)}$ neighbor. In case of the $\mathrm{Y}$-doped $\mathrm{SrZrO}_{3}$, the estimated activation energy is $0.63 \mathrm{eV}$ for the proton movement from the $\mathrm{O}_{(5)}$ neighbor to the $\mathrm{O}_{(3)}$ neighbor, $\Delta \mathrm{H}\left(\mathrm{O}_{(5)}-\mathrm{H}-\mathrm{O}_{(3)}\right)$, and $0.42 \mathrm{eV}$ for the proton movement from the $\mathrm{O}_{(5)}$ neighbor to the $\mathrm{O}_{(7)}$ neighbor, $\Delta \mathrm{H}\left(\mathrm{O}_{(5)}-\mathrm{H}-\mathrm{O}_{(7)}\right)$. In case of the Al-doped $\mathrm{SrZrO}_{3}$, the values of $\Delta \mathrm{H}\left(\mathrm{O}_{(5)}-\mathrm{H}-\mathrm{O}_{(3)}\right)$ and $\Delta \mathrm{H}\left(\mathrm{O}_{(5)}-\mathrm{H}-\right.$ $\mathrm{O}_{(7)}$ ), are $0.32 \mathrm{eV}$ and $0.95 \mathrm{eV}$, respectively. It is considered that the movement from the $\mathrm{O}_{(5)}$ neighbor to the $\mathrm{O}_{(7)}$ neighbor is necessary for proton to diffuse in a long-range distance, otherwise proton would tend to be trapped by an octahedron where an acceptor ion is located in the center. Therefore, the movement from the $\mathrm{O}_{(5)}$ neighbor to the $\mathrm{O}_{(7)}$ neighbor is supposed to be the rate limiting process for proton diffusion. As explained above, the activation energy of $\Delta \mathrm{H}\left(\mathrm{O}_{(5)}-\mathrm{H}-\mathrm{O}_{(7)}\right), 0.42 \mathrm{eV}$, in the $\mathrm{Y}$-doped $\mathrm{SrZrO}_{3}$, is lower than the activation energy of $\Delta \mathrm{H}\left(\mathrm{O}_{(5)}-\mathrm{H}-\mathrm{O}_{(7)}\right), 0.95 \mathrm{eV}$, in the Al-doped $\mathrm{SrZrO}_{3}$. This is in agreement with the experimental results, since the measured activation energy is $0.43 \mathrm{eV}$ in the Y-doped $\mathrm{SrZrO}_{3}$ and $0.97 \mathrm{eV}$ in the Aldoped $\mathrm{SrZrO}_{3} .{ }^{24)}$ As described in the preceding section, the number of mobile protons may change with temperatures up to $800^{\circ} \mathrm{C}(1073 \mathrm{~K})$. So, the measured activation energy may not correspond exactly to that for proton transfer. In this sense, the present results should be understood in a qualitative way but not in a quantitative way.

Thus, from a geometrical viewpoint, $\mathrm{Y}$ is a more preferable acceptor ion than $\mathrm{Al}$ for protonic conduction in $\mathrm{SrZrO}_{3}$. Besides, as mentioned before, local charge states in the octahedron of the Y-doped oxide resemble those of the undoped oxide, which is not the case of the Al-doped oxide. In this study, the presence of oxygen ion vacancies in the oxide is not counted in the calculation because of very poor information in the local ionic arrangements around the vacancy. In view of the electronic structure the vacancy itself works as a donor as shown in our previous paper. ${ }^{27)}$ However, to the best of our knowledge, the vacancy-acceptor complex is little known experimentally as well as theoretically. In the presence of oxygen ion vacancies proton conduction may be enhanced by $\mathrm{OH}^{-}$diffusion as a whole at high temperature, ${ }^{2,47)}$ but at the temperatures lower than $1073 \mathrm{~K}$ there is no evidence of the vacancy effect in $\mathrm{SrZrO}_{3}$. Despite of this uncertainty, the present results of the doping effect on the proton conductivity are supposed to be right qualitatively. 


\section{Summary}

The local electronic structures of pure and doped $\mathrm{SrZrO}_{3}$ are simulated by the DV-X $\alpha$ molecular orbital method. It is shown that the local chemical bond around acceptor ion, M, affects protonic conductivity greatly.

Protonic conductivity tends to decrease with increasing deviation of the net charges on the acceptor ion, $\mathrm{M}$, and the surrounding $\mathrm{O}$ ions. Also, the bond order is a measure of the size change in the $\mathrm{MO}_{6}$ octahedron. Its slight expansion due to a little weakening of the $\mathrm{M}-\mathrm{O}$ bond is preferable for enhancing proton transfer toward the neighboring oxygen sites, $\mathrm{O}_{(i)}$. As the $\mathrm{O}-\mathrm{H}$ molecular bond is inclined toward the $\mathrm{MO}_{6}$ octahedron, such expansion makes the $\mathrm{O}_{(i)}-\mathrm{H}$ interionic distances nearly equal between the neighboring $\mathrm{MO}_{6}$ and $\mathrm{ZrO}_{6}$ octahedra, and reduces the activation energy for proton transfer.

This information of the local chemical bond is indeed a useful guide to the selection of the acceptor ions in proton conducting perovskite-type oxides, since neither the ionic radius nor the electronegativity is a valid parameter for the selection.

\section{Acknowledgments}

The authors acknowledge the Computer Center, Institute for Molecular Science, Okazaki National Institutes for the use of the SX-3/34R computer. This study was supported by a Grant-in-Aid for Scientific Research from the Ministry of Education, Culture, Sports, Science and Technology of Japan, and from the Japan Society for the Promotion of Science (JSPS), and also by the Research Fellowship of JSPS for Young Scientists.

\section{REFERENCES}

1) H. Iwahara, T. Esaka, H. Uchida and N. Maeda: Solid State Ionics 3/4 (1981) 359-363.

2) K. D. Kreuer: Chem. Mater. 8 (1996) 610-641.

3) H. Iwahara, T. Yajima, T. Hibino and H. Uchida: J. Electrochem. Soc. 140 (1993) 1687-1691.

4) N. Kurita, N. Fukatsu and T. Ohashi: J. Jpn. Inst. Met. 58 (1994) 782788.

5) T. Yajima, K. Koide, H. Takai, N. Fukatsu and H. Iwahara: Solid State Ionics 79 (1995) 333-337.

6) K. D. Kreuer: Solid State Ionics 136-137 (2000) 149-160.

7) K. D. Kreuer, St. Adams, W. Münch, A. Fuchs, U. Klock and J. Maier: Solid State Ionics 145 (2001) 295-306.

8) H. Yugami, S. Matsuo and M. Ishigame: Solid State Ionics 77 (1995) 195-200.

9) E. Matsushita and A. Tanase: Solid State Ionics 97 (1997) 45-50.

10) N. Sata, K. Hiramoto and M. Ishigame: Phys. Rev. B 54 (1996) 1579515799.

11) K. S. Knight: Solid State Ionics 127 (2000) 43-48.

12) G. Weber, S. Kapphan and M. Wölecke: Phys. Rev. B 34 (1986) 8406 8417.

13) A. S. Nowick and A. V. Vaysleyb: Solid State Ionics 97 (1997) 17-26.
14) H. Yugami, Y. Shibayama, S. Matsuo, M. Ishigame and S. Shin: Solid State Ionics 85 (1996) 319-322.

15) R. Hempelmann, M. Soetratmo, O. Hartmann and R. Wäpling: Solid State Ionics 107 (1998) 269-280.

16) M. Pionke, T. Mono, W Schweika, T. Springer and H. Schober: Solid State Ionics 97 (1997) 497-504.

17) Th. Matzke, U. Stimming, Ch. Karmonik, M. Soetratmo, R. Hemplemann and F. Güthoff: Solid State Ionics 86-88 (1996) 621-628.

18) W. Münch, G. Seifert, K. D. Kreuer and J. Maier: Solid State Ionics 97 (1997) 39-44.

19) F. Shimojo, K. Hoshino and H. Okazaki: Solid State Ionics 113-115 (1998) 319-323.

20) W. Münch, K. D. Kreuer, St. Adams, G. Seifert and J. Maier: Phase Transitions 68 (1999) 567-586.

21) W. Münch, K. D. Kreuer, G. Seifert and J. Maier: Solid State Ionics 136-137 (2000) 183-189.

22) W. Münch, G. Seifert, K. D. Kreuer and J. Maier: Solid State Ionics 8688 (1996) 647-652.

23) H. Iwahara, T. Yajima, T. Hibino, K. Ozaki and H. Suzuki: Solid State Ionics 61 (1993) 65-69.

24) T. Yajima, H. Suzuki, T. Yogo and H. Iwahara: Solid State Ionics 51 (1992) 101-107.

25) T. Yajima, H. Kazeoka, T. Yogo and H. Iwahara: Solid State Ionics 47 (1991) 271-275

26) H. Yukawa, K. Nakatsuka and M. Morinaga: Solid State Ionics 116 (1999) 89-98.

27) M. Yoshino, K. Nakatsuka, H. Yukawa and M. Morinaga: Solid State Ionics 127 (2000) 109-123.

28) M. Yoshino, Y. Liu, K. Tatsumi, I. Tanaka, M. Morinaga and H. Adachi: Mater. Trans. 43 (2002) 1444-1450.

29) M. Yoshino, Y. Liu, K. Tatsumi, I. Tanaka, M. Morinaga and H. Adachi: Solid State Ionics 162-163 (2003) 127-133.

30) Y. Liu, M. Yoshino, K. Tatsumi, I. Tanaka, M. Morinaga and H. Adachi: Mater. Trans. 46 (2005) 1106-1111.

31) C. Satoko, M. Tsukada and H. Adachi: J. Phys. Soc. Jpn. 45 (1978) 1333-1340.

32) M. Morinaga, N. Yukawa and H. Adachi: J. Phys. Soc. Jpn. 53 (1984) 653-663.

33) R. S. Mulliken: J. Chem. Phys. 23 (1955) 1833-1840.

34) R. S. Mulliken: J. Chem. Phys. 23 (1955) 1841-1846.

35) R. S. Mulliken: J. Chem. Phys. 23 (1955) 2338-2342.

36) R. S. Mulliken: J. Chem. Phys. 23 (1955) 2343-2346.

37) H. Adachi, M. Tsukada and C. Satoko: J. Phys. Soc. Jpn. 45 (1978) 875-883.

38) H. Adachi, S. Shiokawa, M. Tsukada, C. Satoko and S. Sugano: J. Phys. Soc. Jpn. 47 (1979) 1528-1537.

39) M. Tsukada, H. Adachi and C. Satoko: Prog. Surf. Sci. 14 (1983) 113173.

40) A. Ahtee, M. Ahtee, A. M. Glazer and A. W. Hewat: Acta. Cryst. B32 (1976) 3243-3246.

41) M. Yoshino, H. Yukawa and M. Morinaga: Mater. Trans. 45 (2004) 2056-2061.

42) H. D. Megaw: Proc. Phys. Soc. 58 (1946) 133-152.

43) H. J. A. Koopmanns, G. M. H. van de Velde and P. J. Gellings: Acta. Cryst. C39 (1983) 1323-1325.

44) N. Sata, M. Ishigame and S. Shin: Solid State Ionics 86-88 (1996) 629632.

45) C. Karmonik, T. J. Udovic, R. L. Paul, J. J. Rush, K. Lind and R. Hempelmann: Solid State Ionics 109 (1998) 207-211.

46) K. Hiramoto, S. Shin and M. Ishigame: Abstracts of the 16th Meeting on Dynamics of Fast Ions in Solid and Its Evolution for Solid State Ionics (1990) 41.

47) K. D. Kreuer, E. Schönherr and J. Maier: Solid State Ionics 70/71 (1995) 278-284. 